\title{
Cardiotoxicity of Anthracyclines
}

\author{
Daniela Cardinale ${ }^{1 *}$, Fabiani lacopo ${ }^{1}$ and Carlo Maria Cipolla ${ }^{2}$ \\ ${ }^{1}$ Cardioncology Unit, European Institute of Oncology, IRCCS, Milan, Italy, ${ }^{2}$ Cardiology Division, European Institute of \\ Oncology, IRCCS, Milan, Italy
}

OPEN ACCESS

Edited by:

Canan G. Nebigil,

École supérieure de biotechnologie

Strasbourg (ESBS), France

Reviewed by:

Sherry-Ann Brown

Mayo Clinic, United States

Giselle Melendez,

Wake Forest University, United States

*Correspondence:

Daniela Cardinale daniela.cardinale@ieo.it

Specialty section:

This article was submitted to

Cardio-Oncology,

a section of the journal

Frontiers in Cardiovascular Medicine

Received: 14 November 2019

Accepted: 18 February 2020

Published: 18 March 2020

Citation:

Cardinale D, lacopo F and Cipolla CM

(2020) Cardiotoxicity of

Anthracyclines.

Front. Cardiovasc. Med. 7:26.

doi: 10.3389/fcvm.2020.00026
Cardiotoxicity is a feared side effect that may limit the clinical use of anthracyclines. It may indeed affect the quality of life and survival of patients with cancer, regardless of oncological prognosis. This paper provides an overview of anthracycline-induced cardiotoxicity in terms of definition, classification, incidence, risk factors, possible mechanisms, diagnosis, and treatment. We also report effective strategies for preventing cardiotoxicity. In addition, we discuss limiting current approaches, the need for a new classification, and early cardiotoxicity detection and treatment. Probably, anthracycline-induced cardiotoxicity is a continuous phenomenon that starts from myocardial cell injury; it is followed by left ventricular ejection fraction (LVEF) and, if not diagnosed and cured early, progressively leads to symptomatic heart failure. Anthracycline-induced cardiotoxicity can be detected at a preclinical phase. The role of biomarkers, in particular troponins, in identifying subclinical cardiotoxicity and its therapy with angiotensin-converting enzyme inhibitors (mainly enalapril) to prevent LVEF reduction is a recognized and effective strategy. If cardiac dysfunction has already occurred, partial or complete LVEF recovery may still be obtained in case of early detection of cardiotoxicity and prompt heart failure treatment.

Keywords: cardiotoxicity, anthracyclines, early detection, troponin, prevention, reversibility, ACE-inhibitors, beta-blockers

\section{INTRODUCTION}

Anthracyclines are cytostatic antibiotics (1), introduced into the clinical field in the 1960s. As of 2012, anthracyclines were among the most diffused chemotherapeutic agents, and they still represent the base of treatment in many solid cancers and hematological malignancies $(1,2)$.

Unfortunately, anthracyclines are considered the principal culprit drugs behind chemotherapy-induced cardiotoxicity (1-5). The pathognomonic manifestation of anthracycline-induced cardiotoxicity is a hypokinetic cardiomyopathy progressively leading to heart failure, first described in 1967 (6). The onset of anthracycline-cardiomyopathy, also at the pre-clinical stage, may negatively affect the cardiovascular outcome of patients as also limit the chemotherapeutic strategies $(4,5)$.

\section{INCIDENCE AND RISK FACTORS}

The risk of anthracycline-induced heart failure increases as the cumulative dose administered increases: $3-5 \%$ with $400 \mathrm{mg} / \mathrm{m}^{2}$ and as high as $18-48 \%$ at $700 \mathrm{mg} / \mathrm{m}^{2}$ (4). However, there is a different level of risk for each patient scheduled for anthracycline therapy: patients less than 5 years old or more than 65 years old, with prior or concurrent chest irradiation, pre-existing heart disease, or already known cardiovascular risk factors, have an increased risk for cardiotoxicity 
TABLE 1 | Baseline risk factors for anthracycline-induced cardiotoxicity (4, 7).

\begin{tabular}{ll}
\hline Current myocardial disease & $\begin{array}{l}\text { Demographic and other } \\
\text { CV risk factors }\end{array}$ \\
\hline - Heart failure & - Age ( $<5$ or $>65$ years) \\
- Asymptomatic LV dysfunction (LVEF & - Family history of premature CV \\
$<50 \%)$ & disease ( $<50$ years) \\
- Evidence of CAD (previous myocardial & - Arterial hypertension \\
infarction, angina, PCI or CABG, & - Diabetes mellitus \\
myocardial ischemia) & - Hypercholesterolemia \\
- Moderate and severe VHD with LVH or & \\
- LV impairment & \\
- Hypertensive heart disease with LV & \\
- Hypertrophy & \\
- Dilated cardiomyopathy & \\
- Restrictive cardiomyopathy & \\
- Cardiac sarcoidosis with myocardial & \\
involvement & \\
- Significant cardia arrhythmias (AF, \\
ventricular tachyarrhythmias)
\end{tabular}

\begin{tabular}{ll} 
Previous cardiotoxic cancer treatment & Lifestyle risk factors \\
\hline - Prior anthracycline use & - Smoking \\
- Prior radiotherapy to chest & - High alcohol intake \\
or mediastinum & - Obesity \\
& - Sedentary habit
\end{tabular}

$A F$, atrial fibrillation; $C A B G$, coronary artery bypass graft; $C A D$, coronary artery disease; $C V$, cardiovascular; $L V$, left ventricular; $L V E F$, left ventricular ejection fraction; $L V H$, left ventricular hypertrophy; $\mathrm{PCl}$, percutaneous coronary intervention; VHD, valvular heart disease.

(Table 1) (4, 7). Moreover, anthracycline-induced cardiotoxicity risk increases with the use of other agents that may increase its incidence. In particular, trastuzumab, while very effective in treating breast cancer, interferes with myocyte survival pathways, crucial in countering the toxic effects of anthracyclines $(5,7,8)$.

\section{MECHANISMS}

The specific mechanisms of anthracycline cardiotoxicity still remain unclear. A potential mechanism is the generation of reactive oxygen species (ROS), changes in iron metabolism, and Ca2p signaling. In 2014, topoisomerase (Top) $2 \beta$ was indicated as the critical mediator of anthracycline's cardiac toxic effect (9). Top2 can uncoil deoxyribonucleic acid (DNA) filaments during DNA replication, transcription, or recombination. The anthracycline inhibition of Top $2 \beta$ causes mitochondrial dysfunction and leads to activation of cell death pathways and ROS deposit $(2,3,10)$.

The cardiomyocyte has always been considered the main cellular target of anthracycline toxic effect in the heart, as their destruction results in the progressive development of cardiac dysfunction. More recently, however, other cell types-such as cardiac progenitor cells, cardiac fibroblasts, and endothelial cells-have been identified as potential additional targets, creating a more complex and intriguing scenario in the pathogenesis of anthracycline-induced cardiomyopathy
(Figure 1) (11). So far, the principal mechanisms, with potential differential impact and grade of involvement in different cell types, are oxidative stress, DNA damage, senescence, and cell death.

\section{CLASSIFICATION}

A previous and more dated classification identified three distinct types of anthracycline-induced cardiotoxicity (Table 2): acute, occurring after a single dose, or a single course, with the onset of symptoms within 14 days from the end of treatment, which is usually reversible; early-onset chronic, occurring within 1 year, the principal form of cardiotoxicity, from a clinical and epidemiological stand-point, presenting as a dilated-hypokinetic cardiomyopathy, with progressive evolution toward heart failure; and late-onset chronic, developing years, possibly decades, after the end of anthracycline therapy. The two chronic forms are considered irreversible, with a poor prognosis and a limited to heart failure therapy. This classification stems back to early 1980s, and it is mainly based on small retrospective studies reporting the occurrence of heart failure symptoms in childhood cancer survivors (12-14). In particular, in a milestone study, Steinherz et al. reported cases of heart failure occurrence many years after the end of anthracycline-chemotherapy, and the percentage of patients with cardiac dysfunction, as well as the severity of the dysfunction itself, increased in parallel with time elapsed from the end of anthracycline administration (14). However, the clinical relevance of such a classification at present is uncertain, especially when referred to adult populations.

In particular, recent findings challenge this old classification, suggesting that anthracycline-induced cardiotoxicity is potentially a continuous phenomenon, starting at the myocardial cell level, followed by progressive functional decline, progressively leading to overt heart failure. (Figure 2) $(5,8,15)$. To be practical, anthracycline-associated cardiotoxicity is now thought to occur at the time of first exposure, a hypothesis supported by the finding of troponin release after anthracycline administration (16). Clinical presentation may occur years later the initial damage (16-18). Looking at symptoms, the diagnosis may take years ("late" cardiotoxicity). Considering LVEF reduction, it may take months ("early" cardiotoxicity). With the use of circulating biomarkers, such as troponin (pre-clinical myocardial cell damage), prompt identification of cardiotoxicity is possible, allowing for an "acute" form. So far, we are probably observing the evolving stages of the same phenomenon and not three distinct diseases $(15,17,18)$.

\section{DIAGNOSIS AND DEFINITION}

The diagnosis of anthracycline-induced cardiotoxicity has remained the same over the last 60 years. It has always been based on heart failure symptoms, and, later, also on evidence of LVEF drop (echocardiography or multi-gated acquisition scans) $(4,18)$. A former definition adopted was an LVEF absolute decrease higher than $10 \%$ points, associated with a decline $<50 \%$ (5). More recently, the consensus [Plana et al. (19)] defined it 


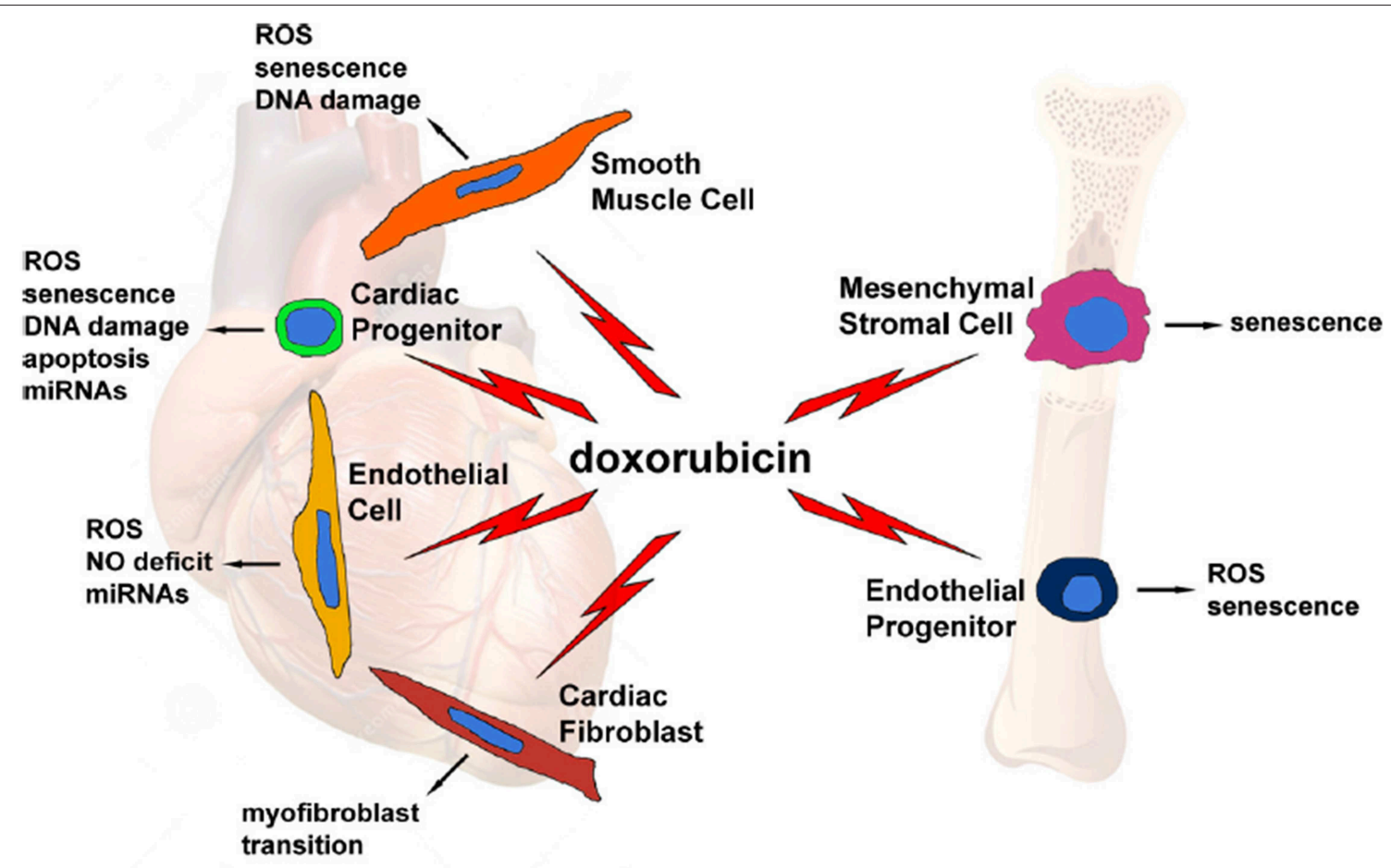

FIGURE 1 | Graphical representation of several doxorubicin-targeted cell types, with potential side effects and cellular and molecular events evoked by the drug. From Cappetta et al. (11).

as an LVEF decrying $>10 \%$ points, with a final value $<53 \%$ (19). In patients at low risk-i.e., without risk factors or a negative cardiovascular history, with an indication to receive a low dose of anthracyclines (total cumulative dose $\leq 240 \mathrm{mg} / \mathrm{m}^{2}$ ) or standard dose followed by trastuzumab-based regimenscardiac monitoring is not suggested by the American Society of Clinical Oncology guidelines. Moreover, they suggest a diagnosis of cardiotoxicity based on clinical symptoms (20). Reasons comprise "medicalization, the possibility of causing stress and anxiety, and costs" to be incurred $(20,21)$. Otherwise, the international cardiological guidelines recommend monitoring of cardiac function by serial LVEF measurements, but do not provide an accurate indication on timing, frequency, modalities, and long-term schedule (7). Moreover, a diagnosis based on symptoms or asymptomatic decrease of LVEF is not only delayed, but also potentially prevents any form of effective prevention, as the cardiac damage may be no longer reversible $(17,18)$.

A recent study evaluating a significant $(n=2,625)$ population scheduled for anthracycline therapy showed that close monitoring of LVEF after chemotherapy allowed nearly all $(98 \%)$ cases of cardiotoxicity to be identified within the first 12 months of follow-up (15). In addition, early treatment with angiotensin-converting enzyme (ACE)-inhibitors (enalapril) and beta-blockers (carvedilol or bisoprolol) enabled normalization of cardiac function in most cases (82\%), but only $11 \%$ of patients who had renormalized LVEF had full recovery-i.e., the same LVEF value as before the start of anthracyclines-while the final $\mathrm{LVEF}$ value in $71 \%$ of patients remained below the baseline value (Figure 3).
TABLE 2 | Old classification of anthracycline-induced cardiotoxicity (7, 12-14).

\begin{tabular}{|c|c|c|c|}
\hline Characteristics & $\begin{array}{l}\text { Acute } \\
\text { cardiotoxicity }\end{array}$ & $\begin{array}{l}\text { Early-onset } \\
\text { chronic } \\
\text { cardiotoxicity }\end{array}$ & $\begin{array}{l}\text { Late-onset } \\
\text { chronic } \\
\text { cardiotoxicity }\end{array}$ \\
\hline Onset & $\begin{array}{l}\text { During or within } 2 \\
\text { weeks after } A C \\
\text { treatment }\end{array}$ & $\begin{array}{l}\text { Within } 1 \text { year after } \\
\text { the completion of } \\
\text { AC treatment }\end{array}$ & $\begin{array}{l}>1 \text { year after the } \\
\text { completion of } A C \\
\text { treatment }\end{array}$ \\
\hline Dose dependent & Unknown & Yes & Yes \\
\hline Clinical features & $\begin{array}{l}\text { Depression of } \\
\text { myocardial } \\
\text { contractility }\end{array}$ & $\begin{array}{l}\text { Dilated/Hypokinetic } \\
\text { cardiomyopathy }\end{array}$ & $\begin{array}{l}\text { Dilated/Hypokinetic } \\
\text { cardiomyopathy }\end{array}$ \\
\hline \multirow[t]{3}{*}{ Course } & Usually reversible & Usually irreversible & Usually irreversible \\
\hline & & $\begin{array}{l}\text { Refractory to } \\
\text { traditional heart } \\
\text { failure therapy }\end{array}$ & $\begin{array}{l}\text { Refractory to } \\
\text { traditional heart } \\
\text { failure therapy }\end{array}$ \\
\hline & & Poor prognosis & Poor prognosis \\
\hline
\end{tabular}

These findings confirm that this approach is limited in identifying reversible cardiotoxicity, probably because left ventricular compensation mechanisms have been exhausted (8). Of great importance, the evidence of a normal LVEF does not exclude the risk of future deterioration of cardiac function.

\section{TREATMENT}

The historical concept that anthracycline-induced cardiotoxicity is irreversible, with a reported mortality rate up to $60 \%$ within 2 


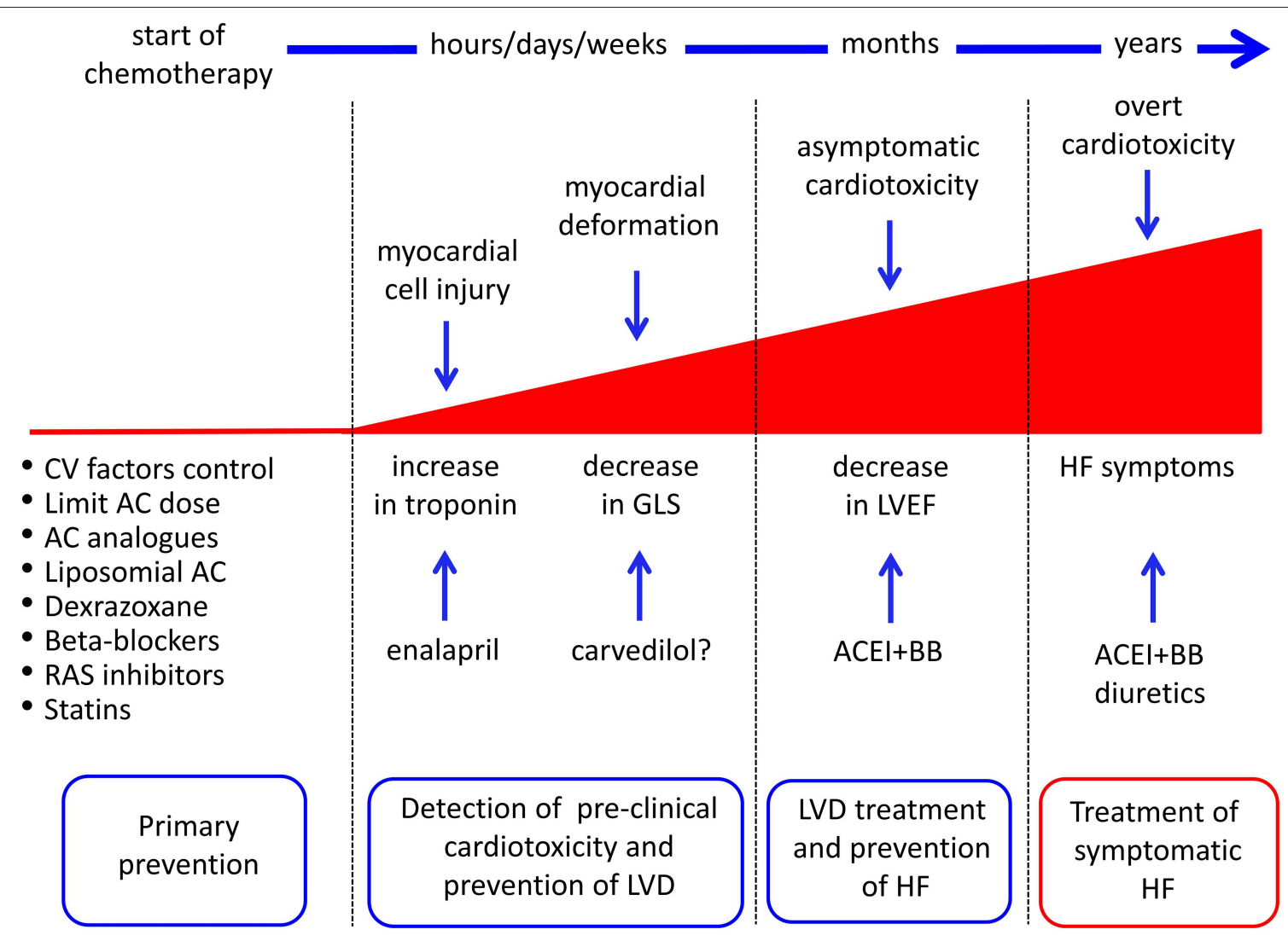

FIGURE 2 | Possible strategies for cancer drug-induced cardiotoxicity detection, prevention, and treatment. AC, anthracyclines; ACEI, angiotensin-converting enzyme inhibitors; BB, beta-blockers; CV, cardiovascular; GLS, global longitudinal strain; HF, heart failure; LVD, left ventricular dysfunction; RAS, renin-angiotensin system. From Cardinale et al. (8).

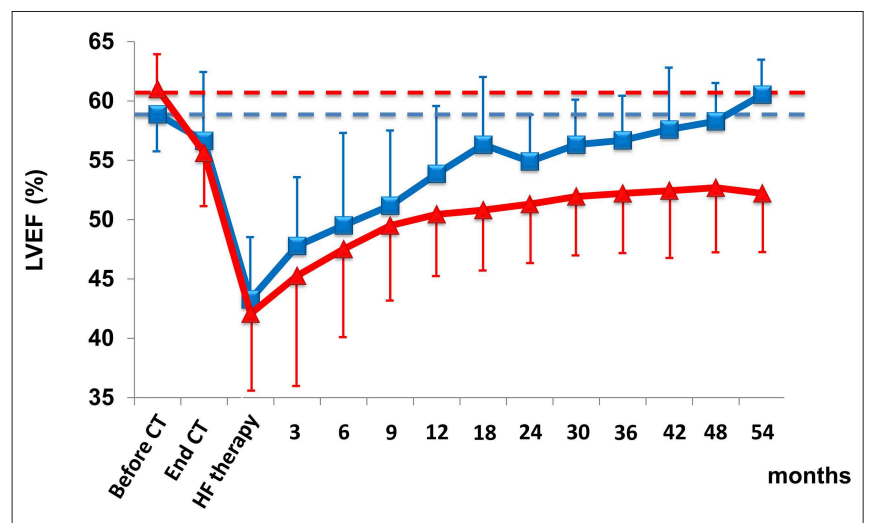

FIGURE 3 | LVEF in patients with cardiotoxicity and with partial (triangle) or full (square) recovery with heart failure therapy. Data are mean \pm SD. CT, chemotherapy; HF, heart failure. From Cardinale et al. (15).

years of diagnosis, is now reconsidered. In particular, this belief is based on seminal studies in which heart failure therapeutic strategies were limited (i.e., digoxin, diuretics), or on studies with small populations, retrospective design, short follow-up, or on case reports $(22-30)$.
Up until 2010, the response to heart failure therapy of patients with anthracycline-induced cardiotoxicity hadn't been thoroughly investigated. Moreover, these kind of patients have been excluded from large randomized trials evaluating the impact of current heart failure therapies (8).

The effectiveness of ACE-inhibitors and beta-blockers has been prospectively assessed in two extensive papers $(15,31)$. In 201 patients with anthracycline-induced cardiotoxicity, an inverse relationship in terms of LVEF improvement has been found between the time interval from the end of chemotherapy and the beginning of heart failure therapy (Figure 4A) (31). LVEF recovery rate was $64 \%$ in those treated early (i.e., within 2 months after the end of chemotherapy); later on, however, this percentage rapidly decreased, with no complete recovery after 6 months. After 12 months, obtaining even partial LVEF improvement was almost impossible (Figure 4B) (31). It emerges that cardiotoxicity is not irreversible, but that reversibility is a matter of time, depending on early diagnosis, allowing prompt treatment. Furthermore, these findings, based on standard cardiac symptoms surveillance, might miss this change (8).

On the contrary, close monitoring and timely treatment with HF therapies have reported that they are critical for functional recovery in a non-selected population treated with anthracycline, allowing early detection of cardiotoxicity in the 


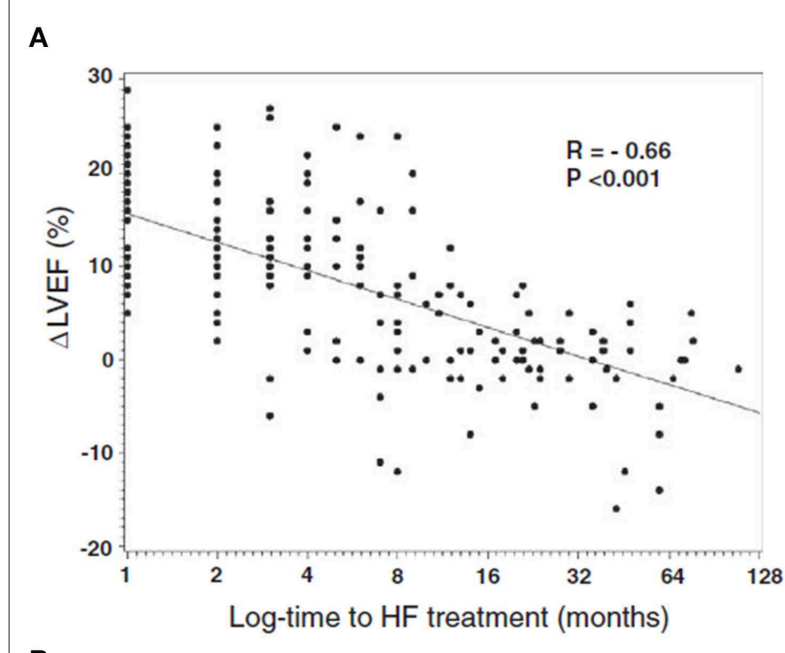

B

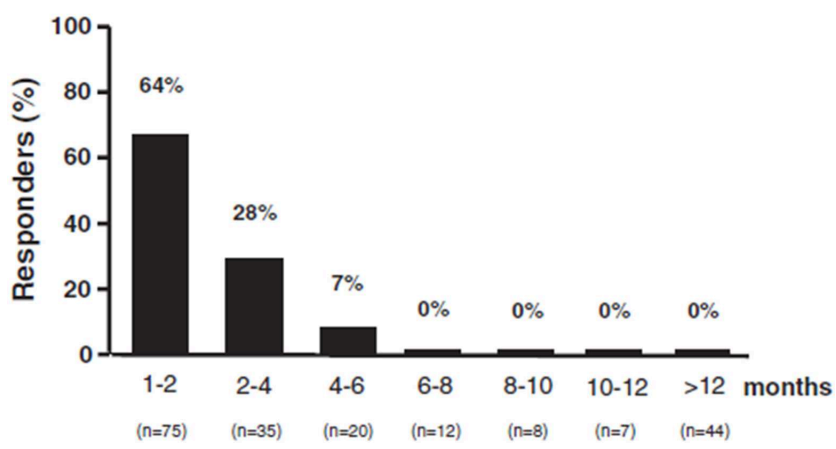

FIGURE 4 | (A) Percentage of patients who recovered (Responders), according to the time elapsed from anthracycline administration and the start of heart failure therapy. (B) Relationship between maximal LVEF during the follow-up period and log time elapsed from chemotherapy and the start of treatment [time-to-heart failure (HF) treatment]. From Cardinale et al. (31).

vast majority of cases during the first year after chemotherapy, with normalization of LVEF (final value of LVEF > 50\%) in $82 \%$ of cases (15). However, only $11 \%$ of patients had a complete restoration (i.e., final LVEF equal to baseline). This highlights the need for detection methods able to identify early cardiotoxicity and for strategies aimed at preventing the development and the progression of left ventricular dysfunction.

\section{PRECLINICAL EARLY DETECTION}

Today, at an early preclinical stage, we can detect cardiotoxicity long before symptoms of heart failure occur and before an asymptomatic drop in LVEF. Most data relate to cardiac biochemical markers: mainly troponins and echocardiography of tissue Doppler and strain $(5,7,8)$.

\section{Troponin Assessment in Anthracycline-Treated Patients}

Troponin may be considered the gold standard biomarker for myocardial injury and cardiotoxicity from different causes/etiologies (32). Troponin has many advantages: elevated cardiac specificity, high sensitivity, availability, and costs respective to imaging methods. Moreover, there are limited variability issues. In this field, several studies have demonstrated that troponins may detect cardiotoxicity in patients treated with anthracyclines (Table 3) (33-56).

The most extensive study included 703 cancer patients, in whom Troponin I (TnI) was assessed before and during the first $72 \mathrm{~h}$ after chemotherapy (early TnI), and after 1 month (late TnI) (38). Three different troponin release patterns were recognized: Troponin I remained within the normal interval in $72 \%$ of patients, rose at only early evaluation in $21 \%$, and increased at early and late assessments in 9\%. Patients with no rise in troponin showed little difference in LVEF and had a good prognosis, with a low incidence of significant adverse heart events (MACE) (1\%) during follow-up. Alternatively, TnIpositive patients had a higher rate of MACE: In particular, severe cardiac dysfunction and a higher rate of MACE were associated with a persistent TnI elevation compared to patients with only a temporary rise $(p<0.001)$. Based on the high negative predictive value (99\%), TnI has been able to safely identify low-risk patients, limiting the need and subsequent costs of close long-term cardiac monitoring $(34,35,38)$. Conversely, TnI-positive patients deserve more stringent monitoring, mainly those showing a persistent TnI increase.

In summary, we can assert that troponin evaluation in patients treated with anthracyclines allows for:

1. Prediction of the development of future left ventricular dysfunction;

2. Prediction of left ventricular dysfunction severity, because the peak value of troponin is closely related to the extent of LVEF reduction;

3. Stratification of cardiac risk after anthracyclines and tailoring of the schedule of post-chemotherapy monitoring of cardiac function;

4. Identification of cardiotoxicity prone patients, in whom a cardioprotective therapy can be considered; and

5. Exclusion of most patients from prolonged cardiologic surveillance.

On the other hand, the identified weakness points are:

1. Repeated assessments of troponins are needed to detect positivity;

2. The ideal timing for troponin detection must still be defined;

3. Standardization of routine troponin use in this clinical setting is a current need; and

4. Timing in which a single sampling of troponin could be obtained.

\section{Other Circulating Biomarkers}

Although patients with pre-treatment levels of natriuretic peptides (BNP and N-terminal prohormone) tend to experience cardiac events (including cardiac dysfunction), the results are sparse $(44,57,58)$.

More recently (57), BNP levels were shown to be significantly higher after every anthracycline cycle in 
TABLE 3 | Clinical studies demonstrating Troponins as predictor of anticancer drug-induced left ventricular dysfunction (33-56).

\begin{tabular}{|c|c|c|c|c|c|c|}
\hline Study (year) & Patients (n.) & Cancer type & Drugs & $\begin{array}{l}\text { Troponin } \\
\text { type }\end{array}$ & Cut off & Timing of assessment \\
\hline Lipshultz et al. (33) & $15^{\star}$ & ALL & $A C$ & $\mathrm{~T}$ & $0.03 \mathrm{ng} / \mathrm{mL}$ & Before CT; 1-3 days after each dose \\
\hline Cardinale et al. (34) & 201 & Various & HD CT & 1 & $0.04 \mathrm{ng} / \mathrm{ml}$ & 0-12-24-36-72 $\mathrm{h}$ after CT \\
\hline Cardinale et al. (35) & 232 & Breast cancer & HD CT & 1 & $0.04 \mathrm{ng} / \mathrm{ml}$ & 0-12-24-36-72 h after CT \\
\hline Auner et al. (36) & 30 & Hematological & HD Cycl & $\mathrm{T}$ & $0.03 \mathrm{ng} / \mathrm{ml}$ & Before CT; $1-14$ days after CT \\
\hline Sandri et al. (37) & 179 & Various & HD CT & 1 & $0.04 \mathrm{ng} / \mathrm{ml}$ & 0-12-24-36-72 $\mathrm{h}$ after CT \\
\hline Cardinale et al. (38) & 703 & Various & HD CT & 1 & $0.04 \mathrm{ng} / \mathrm{ml}$ & 0-12-24-36-72 $\mathrm{h}$ after CT \\
\hline Specchia et al. (39) & 79 & Hematological & $\mathrm{AC}$ & I & $0.15 \mathrm{ng} / \mathrm{ml}$ & Before CT; weekly x 4 times \\
\hline Kilickap et al. (40) & 41 & Various & $\mathrm{AC}$ & $\mathrm{T}$ & $0.10 \mathrm{ng} / \mathrm{ml}$ & Before CT; 3-5 days after 1 st and last dose \\
\hline Lee et al. (41) & 86 & Hematological & $\mathrm{AC}$ & 1 & $0.20 \mathrm{ng} / \mathrm{ml}$ & Before each dose \\
\hline Schmidinger et al. (42) & 74 & Renal cancer & Sunitinib/sorafenib & $\mathrm{T}$ & 0.02 & Before CT, bimonthly, symptoms occurrence \\
\hline Cardinale et al. (43) & 251 & Breast cancer & $\mathrm{AC}, \mathrm{TRZ}$ & 1 & $0.04 \mathrm{ng} / \mathrm{ml}$ & Before and after each cycle \\
\hline Sawaya et al. (44) & 43 & Breast cancer & AC+taxanes+TRZ & HS-I & $0.015 \mathrm{ng} / \mathrm{ml}$ & Before CT; after 3 and 6 months during CT \\
\hline Lipshultz et al. (45) & $205^{\star}$ & ALL & $\mathrm{AC} / \mathrm{AC}+$ dexrazoxane & $\mathrm{I} / \mathrm{T}$ & $\begin{array}{l}\text { Any detectable } \\
\text { amount }\end{array}$ & Before CT; 1-7 days after each dose; end CT \\
\hline Sawaya et al. (46) & 81 & Breast cancer & AC+taxanes+TRZ & HS-I & $30 \mathrm{pg} / \mathrm{mL}$ & Before CT; after 3 and 6 months during CT \\
\hline Draft et al. (47) & 53 & Various & $\mathrm{AC}$ & 1 & $0.06 \mathrm{ng} / \mathrm{ml}$ & Before CT; after 1, 3, 6 months \\
\hline Mornos et al. (48) & 74 & Various & $\mathrm{AC}$ & HS-T & NA & Before CT; after 6, 12, 24, 52 weeks \\
\hline $\begin{array}{l}\text { Mavinkurve-Groothuis } \\
\text { et al. (49) }\end{array}$ & $60^{\star}$ & ALL & $\mathrm{AC}$ & HS-T & $0.01 \mathrm{ng} / \mathrm{mL}$ & Before CT; after 3 and 12 months \\
\hline Ky et al. (50) & 78 & Breast cancer & $\mathrm{AC}+$ taxanes+TRZ & HS-I & NA & Before CT; after 3 and 6 months during CT \\
\hline Mornos et al. (51) & 92 & Various & AC & HS-T & NA & Before CT; after 12 and 36 weeks \\
\hline Putt et al. (52) & 78 & Breast cancer & AC+taxanes+TRZ & HS-I & NA & Before CT; every 3 months (max 15 months) \\
\hline Zardavas et al. (54) & 412 & Breast cancer & AC+taxanes+TRZ & HS-T/US-I & 14 ng/L/40 ng/L & Before CT; week 13, 25, 52; month 18, 24, 30, 36 \\
\hline Olivieri et al. (54) & 99 & Lymphoma & AC/lipoAC & US-I & $0.08 \mathrm{ng} / \mathrm{ml}$ & Before CT; 1, 24-72 $\mathrm{h}$ after each cycle \\
\hline Kitayama et al. (55) & 40 & Breast cancer & $\mathrm{AC} / \mathrm{AC}+\mathrm{TRZ} / \mathrm{TRZ}$ & HS-T & NA & Before CT; every 3 months during CT \\
\hline Shafi et al. (56) & 82 & Breast cancer & $\mathrm{AC}$ & US-I & NA & $1,24 \mathrm{~h}$ after each cycle \\
\hline
\end{tabular}

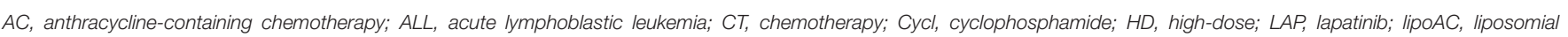
anthracycline; NA, not available; I, troponin I; T, troponin T; TRZ, trastuzumab; HS, high-sensitive; US, ultra-sensitive *, pediatric population.

subjects following cardiac events, while another study demonstrated an association between an increased BNP at $72 \mathrm{~h}$ after chemotherapy and a decrease of LVEF at 1 year (59).

Actually, studies of other biomarkers, including microRNAs (miRNAs), C-reactive protein (CRP), growth differentiation factor-15 (GDF-15), myeloperoxidase (MPO), and galectin3 (Gal-3) have not demonstrated an association between pretreatment biomarker levels and cardiovascular outcomes $(60,61)$.

Regarding monitoring for cardiovascular toxicity during therapy, CRP has shown conflicting findings (50).

More recently, some reports emerged in the field of microRNAs, in particular for miR-1, showing a trend to earlier detection of cardiotoxicity respective to troponin $(62,63)$.

Another study of patients during a period of 10 years after anthracycline therapy did not find an association with Gal-3 and LV dysfunction.

A separate study that included Gal-3 and ST2 found no association with these biomarkers and LVEF 1 year after therapy $(64,65)$.

\section{Tissue Doppler and Strain Echocardiography}

Novel echocardiographic methods have emerged as sensitive parameters in the early identification of cardiotoxicity. In particular, introduction of tissue Doppler and strain imaging techniques can detect early subclinical changes in cardiac function, before LVEF falls (4, 7, 19, 51). In this respect, myocardial deformation (strain imaging) has emerged as a sensitive marker for earlier detection of myocardial dysfunction. In particular, 2D (and more recently, 3D) speckle tracking imaging, allowing the evaluation of global myocardial deformation in the longitudinal axis (global longitudinal strain, GLS, \%), has become a clinical standard. Several papers demonstrated the value of GLS in detecting subclinical myocardial dysfunction, with prognostic relevance in terms of overt LV dysfunction in cancer patients (66-69).

The recent ASE/EACVI consensus defined a relative decrease in GLS of $>15 \%$ from baseline as an indicator of subclinical LV dysfunction and appropriate use criteria for multi-modality imaging include strain for the evaluation of patient candidates for chemotherapy $(19,70)$. Finally, the SUCCOUR trial (first randomized controlled trial of GLS-guided therapy introduction) 
will better define the role of GLS for surveillance for chemotherapy-related cardiac dysfunction (71).

However, these methodologies are not always readily available in all laboratories and seldom used in the routine evaluation of patients receiving anthracyclines (8).

\section{An Integrated Approach to Biomarkers and Cardiac Imaging}

Breakthroughs in laboratory technology have allowed for the introduction of more specific and sensitive troponin assay methods (55), which are able to measure minimal amounts (highsensitivity [HS] dosing systems) of a biomarker that were not detectable with previous methods. This is of pivotal importance, since troponin release as a consequence of anthracycline cardiotoxicity may be minimal, and it is essential to use highprecision dosing systems (72).

The first HS troponin trial enrolled 45 breast cancer patients who were treated with anthracyclines, taxanes, and trastuzumab (44). International and regional myocardial function was assessed at baseline, every 3 months, with tissue Doppler and strain imaging, combined with troponin. A reduction in the longitudinal strain and an increase in HS troponin were predictive of late left ventricular dysfunction after the end of anthracyclines. Notably, the combined assessment of imaging methods and changes in troponin resulted in an increased specificity (93\% combined vs. $73 \%$ for each single method). Ky et al. tested a multi-marker approach in a similar population of breast cancer patients receiving the same anti-cancer therapy regimen (50). All levels of the markers increased significantly from baseline (except for NT-proBNP and Galectin-3). However, at the end of anthracycline therapy, only HS troponin absolute values and changes in troponin and myeloperoxidase levels resulted as predictors of further development of left ventricular dysfunctions.

\section{PRIMARY PREVENTION: REDUCTION OF THE DIRECT CARDIOTOXIC EFFECT (FIGURE 2)}

\section{Limitation of the Maximum Dose of Anthracyclines}

Present oncologic guidelines recommend limiting the total cumulative dose of anthracyclines to $450-550 \mathrm{mg} / \mathrm{ml} \mathrm{(4,}$ 8). However, this may limit the effectiveness of anti-cancer treatment. Moreover, significant variability exists in terms of proneness to anthracycline cardiotoxicity, suggesting that genetic variation might modulate the risk $(5,7,8)$.

\section{Use of Less Cardiotoxic Anthracycline Analogs}

Epirubicin, idarubicin, and mitoxantrone are analogs of anthracyclines that are less cardiotoxic than conventional anthracyclines. Epirubicin cardiotoxicity occurs after higher doses of doxorubicin. However, to obtain the same clinical response, higher doses must be given. In preclinical studies and animal models, idarubicin and mitoxantrone also showed a less cardiotoxic profile than doxorubicin $(5,7)$.

\section{Use of Liposomal Anthracyclines}

In the heart, liposomes cannot get out from the vascular space because capillaries have tight junctions. As the tendency to accumulate in the heart cells is limited, this may reduce the risk of cardiotoxicity. On the contrary, the liposomes reach high concentrations in the tumor site, leaving the circulatory system where tumor growth damages the capillaries itself $(73,74)$.

\section{PRIMARY PREVENTION: PHARMACOLOGIC PREVENTION (FIGURE 2)}

\section{Lifestyle Measures}

Before pharmacologic strategies, primary prevention starts indeed with lifestyle corrective measures.

Since a strong link exists between cancer and cardiovascular risk factor, addressing smoking and sedentary habits (potentially leading to obesity, with a detrimental role especially in the postmenopausal women), as well as high alcohol intake, is pivotal. A healthy diet has been associated with a protective effect in terms of cancer relapses and cardiovascular disease, while smoking has an ominously detrimental effect. While light to moderate alcohol intake has shown a protective impact in terms of cardiovascular disease, the results in terms of risk of developing cardiotoxicity are conflicting (75-77).

Of notice, several pieces of evidence emerged on the protective role of exercise training (and eventually, cardiac rehabilitation) against cardiotoxicity (78).

\section{The Use of Cardioprotection}

The use of cardioprotective drugs to reduce the direct cardiotoxic effect is a potential alternative to anthracycline treatment modifications, dosage limitations, or interruptions $(4,5,8)$.

The hypothesis that iron chelators may reduce the cardiotoxicity induced by anthracyclines suggests that dexrazoxane may be a clinically useful cardioprotective agent $(9,79)$. Doxorubicin is a potent Top2 inhibitor. In the clinical scenario, many studies demonstrated that dexrazoxane significantly reduces cardiotoxicity in adults and pediatric populations: Patients treated with dexrazoxane had a significantly lower incidence of heart failure than untreated patients. Apart from patients with metastatic breast cancer treated with doses of doxorubicin $>300 \mathrm{mg} / \mathrm{mq}$ and despite previous findings, dexrazoxane is not routinely used in clinical practice, because suspected of interfering with the anti-tumor effects and by the occurrence of secondary malignancies. In September 2011, the outcome of a referral (80) that recommended several restrictions on dexrazoxane use in both children and adults with cancer was published. However, several new trials on the benefit-risk of dexrazoxane have been published from then (81-83). So far, dexrazoxane results an effective cardioprotector when administered with anthracycline chemotherapy being not associated with a reduction in anti-tumor efficacy or survival or a relevant increased risk of second primary malignancies, and can 
be recommended as a cardioprotector particularly for children and adolescents for whom the development of anthracyclineinduced cardiotoxicity could have a crucial prognostic impact. These studies contributed to the CHMP's decision to remove the contraindication on Cardioxane (84).

Macedo et al. recently published a systematic review and metaanalysis of nine trials (seven randomized and two retrospective non-randomized trials) on the efficacy of dexrazoxane in patients with breast cancer treated with anthracyclines (with or without trastuzumab). Despite the quality of available evidence remaining low, dexrazoxane was shown to reduce the risk of heart failure and cardiac events, independently from previous exposure to anthracyclines. The oncological response and survival rates were not affected by dexrazoxane (85).

Other potentially cardioprotective agents have been studied in animal models and small clinical studies. Preliminary data are promising, but they need to be ratified by further extensive studies $(2,5,7,8)$.

\section{The Use of Cardiovascular Agents}

Several heart failure drugs have been shown to be effective in terms of cardioprotection against anthracylines (Table 4) (86-98).

Overall, a recent meta-analysis of randomized clinical trials of adult patients that underwent chemotherapy and cardiovascular therapies vs. placebo with follow-up (17 trials, 1,984 patients) showed higher (although with small changes) LVEF values at follow-up in cancer patients receiving neurohormonal therapies (99).

\section{Beta-Blockers}

The non-cardioselective beta-blocker carvedilol is cardioprotective against anthracyclines toxicity. In vitro studies and a small randomized clinical trial, the drug was able to prevent the development of ventricular dysfunction (86). In breast cancer patients, carvedilol blunted strain abnormalities and the increase in troponin, preserving diastolic function, after anthracycline use (100). However, the drug failed to prevent an LVEF reduction $>10 \%$ (101). It appears that carvedilol's efficacy is linked to its antioxidant activity rather than its beta-blocking action. Indeed, a comparative study of carvedilol and atenolol, a selective $\beta 1$ antagonist with no antioxidant properties, showed that carvedilol-but not atenolol-prevented mitochondrial damage and mitigated the ultrastructural changes associated with doxorubicin $(8,102)$.

Nebivolol, a selective $\beta 1$ antagonist with vasodilatory properties, started 7 days before anthracyclines and continued for 6 months in 27 patients with breast cancer prevented a significant decrease of LVEF and an increase of NT-proBNP (87). In a retrospective study including 106 breast cancer patients, a reduced incidence of heart failure over a 5-year follow-up period was associated with the continuation of beta-blocker therapy during oncology treatment-including anthracyclines (88). Existing data indicate, from preclinical studies, that

TABLE 4 | Cardiovascular drugs showing a prophylactic effect against anticancer therapy-induced LVD in adult cancer populations.

\begin{tabular}{|c|c|c|c|c|c|c|}
\hline Study (year) & Study design/follow-up & $N$ & Cancer type & Drugs & Intervention & Results \\
\hline \multicolumn{7}{|l|}{ BETA-BLOCKERS } \\
\hline Kalay et al. (86) & RCT/6 months & 50 & Various & $A C$ & Carvedilol & No LVEF $\downarrow$ \\
\hline Kaya et al. (87) & RCT/6 months & 45 & Breast cancer & $\mathrm{AC}$ & Nebivolol & No LVEF and NT-proBNP $\uparrow$ \\
\hline Seicean et al. (88) & Retrospective/5 years & 318 & Breast cancer & AC,TRZ & Beta-blockers & $\mathrm{HF} \downarrow$ \\
\hline Pituskin et al. (89) & RCT/12 months & 99 & Breast cancer & $\mathrm{CT}+\mathrm{TRZ}$ & Bisoprolol & No LVEF $\downarrow$ \\
\hline \multicolumn{7}{|l|}{ ACEI } \\
\hline Cardinale et al. (90) & RCT/12 months & 114 & Various & HD CT & Enalapril & No LVEF $\downarrow ;$ MACE incidence $\downarrow$ \\
\hline Pituskin et al. (89) & RCT/12 months & 99 & Breast cancer & $\mathrm{CT}+\mathrm{TRZ}$ & Perindopril & No LVEF $\downarrow$ \\
\hline \multicolumn{7}{|l|}{ ARB } \\
\hline Nakamae et al. (91) & $\mathrm{RCT} / 7$ days & 40 & $\mathrm{NHL}$ & $A C$ & Valsartan & No LVEDD $\uparrow ;$ no BNP and ANP $\uparrow ;$ no QT $\uparrow$ \\
\hline Cadeddu et al. (92) & RCT/18 months & 49 & Various & $\mathrm{AC}$ & Telmisartan & 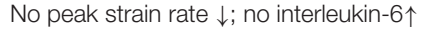 \\
\hline Gulati et al. (93) & RCT/1.5-16 months & 120 & Breast cancer & $A C+T x+T R Z$ & Candesartan & No LVEF $\downarrow$ \\
\hline \multicolumn{7}{|c|}{ ALDOSTERONE ANTAGONISTS } \\
\hline Akpek et al. (94) & RCT/6 months & 83 & Breast cancer & $A C$ & Spironolactone & No LVEF $\downarrow ;$ no TNI and BNP $\uparrow$; \\
\hline \multicolumn{7}{|l|}{ ACEI + BETA-BLOCKERS } \\
\hline Bosh et al. (95) & RCT/6 months & 90 & Hematological & $A C$ & Enalapril + carvedilol & No LVEF $\downarrow ;$ death $\downarrow ;$ HF $\downarrow$ \\
\hline \multicolumn{7}{|l|}{ STATINS } \\
\hline Acar et al. (96) & RCT/6 months & 40 & Hematological & $A C$ & Atorvastatin & No LVEF $\downarrow$ \\
\hline Seicean et al. (97) & Retrospective/5 years & 67 & Breast cancer & $\mathrm{AC}$ & Statins & No HF $\downarrow$ \\
\hline Chotenimitkhun et al. (98) & $\mathrm{PO}$ & 51 & Various & $\mathrm{AC}$ & Atorvastatin/simvastatin & No LVEF $\downarrow$ \\
\hline
\end{tabular}

ACEl, angiotensin-converting enzyme inhibitor; ANP, atrial natriuretic peptide; ARB, angiotensin receptor blocker; BNP, brain natriuretic peptide; HD CT, high-dose chemotherapy; LVD,

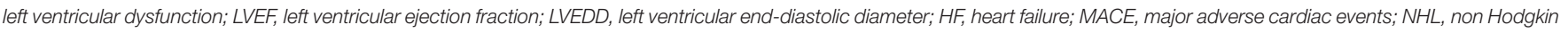
Iymphoma; NT-proBNP, N-terminal-proBNP; QT, QT interval; PO, prospective observational; RCT, randomized controlled trial; TX, taxanes; TNI, troponin I; TRZ, trastuzumab. 
cardio-specific beta blockers offer superior protection against anthracycline damage than non-cardioselective ones (8).

\section{ACE-Inhibitors and Sartans}

Experimental data demonstrated a crucial role of the reninangiotensin system (RAS) in the development and progression of cardiomyopathy induced by anthracyclines (90). Valsartan, administered in combination with anthracyclines, blunted natriuretic peptides increase, the increase in chamber size in patients with non-Hodgkin's lymphoma treated doxorubicin (91). The authors hypothesized a direct inhibition of the drug, independent from hemodynamic effects $(8,90)$.

Telmisartan, started before epirubicin, was able to prevent strain reduction and inflammatory markers increase because of its RAS blocking action, but also because of its anti-inflammatory and anti-oxidant properties (92).

In the PRADA (Prevention of Cardiac Dysfunction during Adjuvant Breast Cancer Therapy) trial candesartan-but not metoprolol-administrated with adjuvant chemotherapy including anthracyclines, with or without trastuzumab, can protect against an early decline in LVEF, assessed with cardiac MRI (93).

The MANTICORE-101 study (Multi-disciplinary Approach to Novel Therapies in Cardiology Oncology Research) tested the use of perindopril vs. bisoprolol in the prevention of left ventricular remodeling, defined as an increase in end-diastolic diameters and primary study point, and of left ventricular dysfunction in HER2+ breast cancer patients treated with trastuzumab prior to anthracycline (89). Neither drug prevent left ventricular remodeling; however, the use of both drugs was associated with a preserved left-ventricular function in multivariate analysis.

The combination of enalapril and carvedilol have been tested in the OVERCOME study (preventiOn of left-ventricular dysfunction with enalapril and carvedilol). The study involved 90 patients treated with anthracyclines, with malignant hemopathies. LVEF didn't change in the intervention group after 6 months, but decreased significantly in controls. In addition, the intervention group had a lower rate of combined death or heart failure or death, heart failure, and a final LVEF of $<45 \%$ (95).

\section{Aldosterone Antagonists}

A recent randomized trial, including 43 breast cancer patients, evaluated the use of spironolactone vs. placebo. Spironolactone was started 1 week before anthracyclines. Three weeks after the end of chemotherapy, the treated group did not show relevant variations in LVEF and rise in troponin I and NT-proBNP (94). In ELEVATE (Effect of Eplerenone on Left Ventricular Diastolic Function in Women Receiving Anthracyclines for Breast Cancer), a recent randomized placebo-controlled trial, administration of eplerenone for 6 months was not associated with significant differences in ventricular function compared with placebo in patients with breast cancer treated with anthracyclines (103).

\section{Statins}

The effect of statins on cardiotoxicity of anthracyclines is most likely due to their pleiotropic effect, and in particular, to their antioxidant properties (8). Forty hematologic cancer patients with no history of heart disease were randomized to receive atorvastatin or placebo before the onset of anthracyclines (95). The dosage was $40 \mathrm{mg} /$ day, regardless of the levels of cholesterol, and lasted for 6 months. During the follow-up, a reduction of the high-sensitivity reactive $C$ protein level and no significant changes in LVEF were observed in the statin group.

Conversely, the LVEF value in the control group resulted in a significant reduction from the baseline. The protective effect of statins also emerged when chemotherapy was started in patients already receiving statins for the prevention of cardiovascular disease (96). In a retrospective observational study of 67 breast cancer patients treated with anthracycline, statin therapy continued to be associated with significant reduction in the risk of heart failure and cardiac-related mortality during follow-up. More recently, patients on statin therapy for the prevention of cardiovascular disease reported a smaller drop in LVEF at 6 months in a retrospective observational study, including 51 patients with breast cancer or hematological malignancies treated with anthracyclines (97).

\section{Perspectives}

A recent study identified the molecular and cellular signature of dose-dependent, doxorubicin-mediated cardiotoxicity and provided evidence that prokineticin receptor (PKR-1)-1, acting at myocardial and vascular level, is a promising target to combat cardiotoxicity of cancer treatments (104).

Since G protein-coupled receptors (GPCRs) are a target of $40 \%$ of clinically used drugs and newly identified cardioprotective agents that bind GPCRs of adrenalin, adenosine, melatonin, ghrelin, galanin, gpelin, prokineticin, and cannabidiol may further aid in the cardioprotective task (105).

\section{PREVENTION IN SELECTED HIGH-RISK PATIENTS}

Prevention may be an option for all patients who are candidates for cardiotoxic therapy (primary prevention) or restricted to patients with preclinical symptoms of cardiotoxicity, with the advantage of limiting prophylactic therapy to a small number of patients (also reducing the side effects of preventive therapy, i.e., hemodynamic effects) (Figure 2).

A randomized trial has tested the cardioprotective capacity of enalapril, involving 473 patients with different types of cancers treated with high-dose chemotherapy (90). 114 patients showed an increase in troponin and were randomized for treatment with or without enalapril. After the end of chemotherapy, enalapril was begun, titrated as tolerated, and continued for 1 year. No patients in the enalapril-treated group showed a decrease in LVEF by 10 absolute points below the value of $50 \%$-the study's primary endpoint-and the incidence of major cardiac events was remarkably small (Figure 5). Of note, in the enalapril community, the LVEF value was still the same as the baseline 
value in $80 \%$ of cases after a follow-up duration of 12 months, showing that enalapril can be a very effective drug in the complete preservation of systolic function in this population.

Two studies are currently evaluating the efficacy of carvedilol as a preventive therapy in a selected patient with a deterioration in the strain parameter. For Research NCT02177175 (Carvedilol for the Prevention of Anthracyclines/Anti-HER2 TherapyAssociated Cardiotoxicity between Women with HER2+ breast cancer Using Myocardial Strain), the primary endpoint is the identification of a reduced LVEF value during the 1-year followup. At Northwestern University of Chicago, the research is still hiring.

\section{PRIMARY VS. SECONDARY PREVENTION}

Enalapril, which began early after the increase in troponin during anthracycline chemotherapy and continued for 12 months, is an effective therapy to avoid left ventricular dysfunction and subsequent heart events (90). Repeated assessment, however, is needed to detect an increase in troponin, as the marker may increase at different times after infusion with therapy (dose of anthracycline and schedules). Primary prevention, applied to all anthracycline-treated patients, does not pose this downside. The ICOSONE (International CardioOncology Society-One) randomized trial prospectively compared the efficacy of two different approaches, to test whether enalapril, initiated in all patients before chemotherapy (Prevention Group), was able to prevent troponin rise and further the development of left ventricular dysfunction, and to test whether this strategy was more successful than enalapril initiated only after troponin elevation during chemotherapy (Troponin-triggered Group) (106). The study included 273 patients from 21 different Centers of Oncology. The most-often administered anthracyclines were epirubicin and doxorubicin. During chemotherapy and the 12-month follow-up, no significant reduction in LVEF and a minimal incidence of cardiovascular events were detected in both groups. Only three patients experienced cardiotoxicity defined as a $10 \%$ reduction in LVEF, below $50 \%$ value.

In brief, the main result of the study was that the two approaches appear to be similarly effective in preventing left ventricular dysfunction and adverse cardiac events, endorsing the use of enalapril in averting anthracycline-induced cardiotoxicity, irrespectively from the strategy used.

Which strategy is best? Secondary prevention (i.e., troponin driven) has the limitation of repeated blood samplings. Nevertheless, considering the high negative predictive value of troponin $(34,35,37,38)$, this strategy appears warranted and cost-effective, as it permits the exclusion of low-risk patients (patients without troponin rise, the vast majority) from longterm monitoring programs based on imaging techniques with a relevant cost-benefit ratio by reducing "medicalization, distress,

TABLE 5 | Pros and Cons of primary prevention vs. secondary prevention with enalapril (83).

\begin{tabular}{ll}
\hline $\begin{array}{l}\text { Primary prevention } \\
\text { with enalapril }\end{array}$ & Enalapril in troponin + patients \\
\hline PROS: & PROS: \\
- Very low incidence LVD \& MACE & - Very low incidence LVD \& MACE \\
- Troponin assessment not required & - Monitoring during up-titration in \\
& about 20\% pts \\
& - Only pts at high-risk exposed to side \\
& effects \\
& - FU monitoring not required in \\
& troponin negative patients \\
CONS: & COW cost-benefit ratio \\
- Monitoring during up-titration in 100\% & - Repeated TNI assessment \\
- All pts exposed to side effects & \\
- High monitoring required in all pts & \\
\hline
\end{tabular}

$L V D$, left ventricular dysfunction; MACE, major adverse cardiac events; FU, follow-up; TNI, troponin I.
A

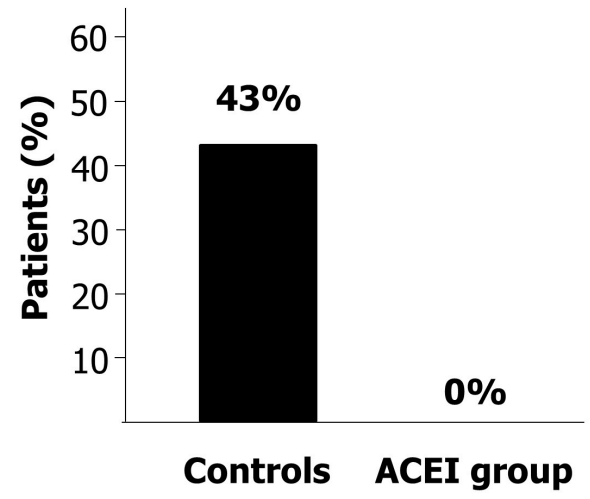

B

CARDIAC EVENTS

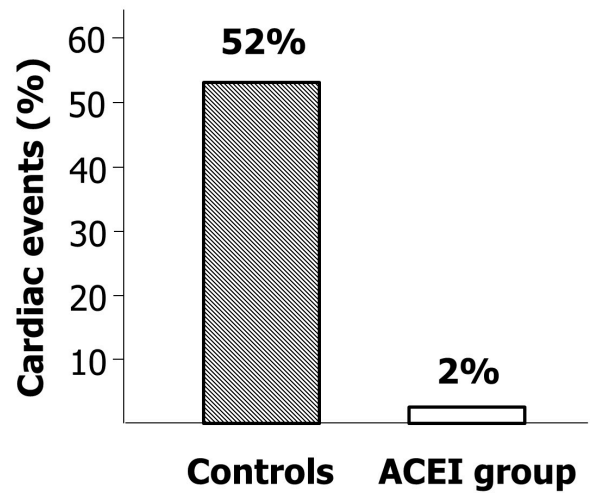

FIGURE 5 | (A) Percentage of patients developing cardiac dysfunction in the enalapril-treated group (ACEl Group) and controls. (B) Incidence of cardiac events in patients treated with ACEI Group and in Controls. Modified from Cardinale et al. (90). 
anxiety, and costs" (21). Primary prevention, although not needing a repeated evaluation of troponin during chemotherapy, can be hard in terms of clinical surveillance during the drug uptitration to include $100 \%$ of patients. Finally, it may expose to potential side effects all those low-risk subjects for cardiotoxicity (Table 5) (106).

\section{CONCLUSION}

Anthracycline-induced cardiotoxicity is still a significant problem that compromises the quality of life and overall survival of cancer patients. However, recent findings demonstrate that this form of cardiomyopathy is mostly reversible with early detection and prompt therapeutic introduction strategy. Probably, anthracycline-induced cardiotoxicity is a single and continuous phenomenon, from cellular to clinical stage, starting with myocardial cell injury, followed by progressive LVEF decline and, potentially, overt heart failure. The current standard for monitoring cardiac function (periodic assessment of LVEF), detects cardiotoxicity at a late stage when a significant impairment has already occurred, precluding the chance of effectively prevent and treat its development.

The use of troponins to identify patients with subclinical cardiotoxicity combined with early treatment with ACE-

\section{REFERENCES}

1. Octavia Y, Tocchetti CG, Gabrielson KL, Janssens S, Crijns HJ, Moens AL. Doxorubicin-induced cardiomyopathy: from molecular mechanisms to therapeutic strategies. J Mol Cell Cardiol. (2012) 52:1213-25. doi: 10.1016/j.yjmcc.2012.03.006

2. Henriksen PA. Anthracycline cardiotoxicity: an update on mechanisms, monitoring and prevention. Heart. (2018) 104:971-77. doi: 10.1136/heartjnl-2017-312103

3. Yeh ET, Chang HM. Oncocardiology-past, present, and future: a review. JAMA Cardiol. (2016) 1:1066-72. doi: 10.1001/jamacardio.2016.2132

4. Curigliano G, Cardinale D, Dent S, Criscitiello C, Aseyev O, Lenihan D, et al. Cardiotoxicity of anticancer treatments: epidemiology, detection, and management. CA Cancer J Clin. (2016) 66:309-25. doi: 10.3322/caac.21341

5. Bloom MW, Hamo CE, Cardinale D, Ky B, Nohria A, Baer L, et al. Cancer therapy-related cardiac dysfunction and heart failure: part 1: definitions, pathophysiology, risk factors, and imaging. Circ Heart Fail. (2016) 9:e002661. doi: 10.1161/CIRCHEARTFAILURE.115.002661

6. Tan C, Tasaka H, Yu KP, Murphy ML, Karnofsky DA. Daunomycin, an antitumor antibiotic, in the treatment of neoplastic disease. Clinical evaluation with special reference to childhood leukemia. Cancer. (1967) 20:333-53. doi: 10.1002/1097-0142(1967)20:3333::aid-cncr28202003023.0. co;2-k

7. Zamorano JL, Lancellotti P, Rodriguez Munoz D, Aboyans V, Asteggiano R, Galderisi M, et al. 2016 ESC Position Paper on cancer treatments and cardiovascular toxicity developed under the auspices of the ESC committee for practice guidelines: the task force for cancer treatments and cardiovascular toxicity of the European Society of Cardiology (ESC). Eur J Heart Fail. (2017) 19:9-42. doi: 10.1002/ejhf.654

8. Cardinale D, Biasillo G, Cipolla CM. Curing cancer, saving the heart: a challenge that cardioncology should not miss. Curr Cardiol Rep. (2016) 18:51. doi: 10.1007/s11886-016-0731-Z

9. Zhang S, Liu X, Bawa-Khalfe T, Lu LS, Lyu YL, Liu LF, et al. Identification of the molecular basis of doxorubicin-induced cardiotoxicity. Nat Med. (2012) 18:1639-42. doi: 10.1038/nm.2919 inhibitors occurrence appears to be an effective method to prevent anthracycline-related left ventricular dysfunction and cardiac events.

Finally, adoption of internal procedures, shared in a multi-disciplinary team, may actively aid in optimizing patient management. In this respect, a direct relationship with the laboratory medicine service for the assessment of troponin values during chemotherapy and the availability of a cardiologist and a dedicated nurse staff should always mix with an active collaboration with the referral oncologist/hematologist (possibly, surgeon) for updates and remains of pivotal importance $(107,108)$.

\section{AUTHOR CONTRIBUTIONS}

DC, FI, and CC contributed conception, design of the review, and wrote the first draft. All authors contributed to manuscript revision, read, and approved the submitted version.

\section{FUNDING}

The present paper was funded by the European Institute of Oncology.

10. Vejpongsa P, Yeh ET. Prevention of anthracycline-induced cardiotoxicity: challenges and opportunities. J Am Coll Cardiol. (2014) 64:938-45. doi: 10.1016/j.jacc.2014.06.1167

11. Cappetta D, Rossi F, Piegari E, Quaini F, Berrino L, Urbanek K, et al. Doxorubicin targets multiple players: a new view of an old problem. Pharmacol Res. (2018) 127:4-14. doi: 10.1016/j.phrs.2017.03.016

12. Giantris A, Abdurrahman L, Hinkle A, Asselin B, Lipshultz SE. Anthracycline-induced cardiotoxicity in children and young adults. Crit Rev Oncol Hematol. (1998) 27:53-68. doi: 10.1016/S1040-8428(97)10007-5

13. Grenier MA, Lipshultz SE. Epidemiology of anthracycline cardiotoxicity in children and adults. Semin Oncol. (1998) 25(4 Suppl. 10):72-85.

14. Steinherz LJ, Steinherz PG, Tan CT, Heller G, Murphy ML. Cardiac toxicity 4 to 20 years after completing anthracycline therapy. JAMA. (1991) 266:16727. doi: 10.1001/jama.266.12.1672

15. Cardinale D, Colombo A, Bacchiani G, Tedeschi I, Meroni CA, Veglia F, et al. Early detection of anthracycline cardiotoxicity and improvement with heart failure therapy. Circulation. (2015) 131:1981-8. doi: 10.1161/CIRCULATIONAHA.114.013777

16. Eschenhagen T, Force T, Ewer MS, de Keulenaer GW, Suter TM, Anker SD, et al. Cardiovascular side effects of cancer therapies: a position statement from the heart failure association of the European society of cardiology. Eur J Heart Fail. (2011) 13:1-10. doi: 10.1093/eurjhf/hfq213

17. Cardinale D, Biasillo G, Salvatici M, Sandri MT, Cipolla CM. Using biomarkers to predict and to prevent cardiotoxicity of cancer therapy. Expert Rev Mol Diagn. (2017) 17:245-56. doi: 10.1080/14737159.2017. 1283219

18. Cardinale D, Cipolla CM. Chemotherapy-induced cardiotoxicity: importance of early detection. Expert Rev Cardiovasc Ther. (2016) 14:1297-9. doi: 10.1080/14779072.2016.1239528

19. Plana JC, Galderisi M, Barac A, Ewer MS, Ky B, Scherrer-Crosbie $\mathrm{M}$, et al. Expert consensus for multimodality imaging evaluation of adult patients during and after cancer therapy: a report from the American society of echocardiography and the European association of cardiovascular imaging. Eur Heart J Cardiovasc Imaging. (2014) 15:1063-93. doi: 10.1093/ehjci/jeu192 
20. Armenian SH, Lacchetti C, Barac A, Carver J, Constine LS, Denduluri N, et al. Prevention and monitoring of cardiac dysfunction in survivors of adult cancers: American society of clinical oncology clinical practice guideline. $J$ Clin Oncol. (2017) 35:893-911. doi: 10.1200/JCO.2016.70.5400

21. Levis BE, Binkley PF, Shapiro CL. Cardiotoxic effects of anthracycline-based therapy: what is the evidence and what are the potential harms? Lancet Oncol. (2017) 18:e445-56. doi: 10.1016/S1470-2045(17)30535-1

22. Felker GM, Thompson RE, Hare JM, Hruban RH, Clemetson DE, Howard $\mathrm{DL}$, et al. Underlying causes and long-term survival in patients with initially unexplained cardiomyopathy. N Engl J Med. (2000) 342:1077-84. doi: 10.1056/NEJM200004133421502

23. Saini J, Rich MW, Lyss AP. Reversibility of severe left ventricular dysfunction due to doxorubicin cardiotoxicity. Report of three cases. Ann Intern Med. (1987) 106:814-6. doi: 10.7326/0003-4819-106-6-814

24. Jensen BV, Nielsen SL, Skovsgaard T. Treatment with angiotensin-converting-enzyme inhibitor for epirubicininduced dilated cardiomyopathy. Lancet. (1996) 347:297-9. doi: 10.1016/S0140-6736(96)90469-9

25. Fazio S, Palmieri EA, Ferravante B, Bone F, Biondi B, Sacca L. Doxorubicininduced cardiomyopathy treated with carvedilol. Clin Cardiol. (1998) 21:777-9. doi: 10.1002/clc.4960211017

26. Noori A, Lindenfeld J, Wolfel E, Ferguson D, Bristow MR, Lowes BD. Beta-blockade in adriamycin-induced cardiomyopathy. J Card Fail. (2000) 6:115-9. doi: 10.1054/jcaf.2000.7505

27. Jensen BV, Skovsgaard T, Nielsen SL. Functional monitoring of anthracycline cardiotoxicity: a prospective, blinded, long-term observational study of outcome in 120 patients. Ann Oncol. (2002) 13:699-709. doi: 10.1093/annonc/mdf132

28. Mukai Y, Yoshida T, Nakaike R, Mukai N, Iwato K, Kyo T, et al. Five cases of anthracycline-induced cardiomyopathy effectively treated with carvedilol. Intern Med. (2004) 43:1087-8. doi: 10.2169/internalmedicine. 43.1087

29. Tallaj JA, Franco V, Rayburn BK, Pinderski L, Benza RL, Pamboukian $\mathrm{S}$, et al. Response of doxorubicin-induced cardiomyopathy to the current management strategy of heart failure. J Heart Lung Transplant. (2005) 24:2196-201. doi: 10.1016/j.healun.2004.12.108

30. Tabet JY, Meurin P, Ben Driss A, Berthaux X, Weber H, Renaud N, et al. Beta-blockade intolerance in anthracycline-induced cardiomyopathy. Int $J$ Cardiol. (2006) 106:132-4. doi: 10.1016/j.ijcard.2004.12.052

31. Cardinale D, Colombo A, Lamantia G, Colombo N, Civelli M, de Giacomi $\mathrm{G}$, et al. Anthracycline-induced cardiomyopathy: clinical relevance and response to pharmacologic therapy. J Am Coll Cardiol. (2010) 55:213-20. doi: 10.1016/j.jacc.2009.03.095

32. O'Brien PJ. Cardiac troponin is the most effective translational safety biomarker for myocardial injury in cardiotoxicity. Toxicology. (2008) 245:206-18. doi: 10.1016/j.tox.2007.12.006

33. Lipshultz SE, Rifai N, Sallan SE, Lipsitz SR, Dalton V, Sacks $\mathrm{DB}$, et al. Predictive value of cardiac troponin $\mathrm{T}$ in pediatric patients at risk for myocardial injury. Circulation. (1997) 96:2641-8. doi: 10.1161/01.CIR.96.8.2641

34. Cardinale D, Sandri MT, Martinoni A, Tricca A, Civelli M, Lamantia G, et al. Left ventricular dysfunction predicted by early troponin I release after high-dose chemotherapy. J Am Coll Cardiol. (2000) 36:517-22. doi: 10.1016/S0735-1097(00)00748-8

35. Cardinale D, Sandri MT, Martinoni A, Borghini E, Civelli M, Lamantia $\mathrm{G}$, et al. Myocardial injury revealed by plasma troponin I in breast cancer treated with high-dose chemotherapy. Ann Oncol. (2002) 13:710-5. doi: 10.1093/annonc/mdf170

36. Auner HW, Tinchon C, Linkesch W, Tiran A, Quehenberger F, Link H, et al. Prolonged monitoring of troponin $\mathrm{T}$ for the detection of anthracycline cardiotoxicity in adults with hematological malignancies. Ann Hematol. (2003) 82:218-22. doi: 10.1007/s00277-003-0615-3

37. Sandri MT, Cardinale D, Zorzino L, Passerini R, Lentati P, Martinoni A, et al. Minor increases in plasma troponin I predict decreased left ventricular ejection fraction after high-dose chemotherapy. Clin Chem. (2003) 49:24852. doi: 10.1373/49.2.248

38. Cardinale D, Sandri MT, Colombo A, Colombo N, Boeri M, Lamantia G, et al. Prognostic value of troponin I in cardiac risk stratification of cancer patients undergoing high-dose chemotherapy. Circulation. (2004) 109:274954. doi: 10.1161/01.CIR.0000130926.51766.CC

39. Specchia G, Buquicchio C, Pansini N, Di Serio F, Liso V, Pastore D, et al. Monitoring of cardiac function on the basis of serum troponin I levels in patients with acute leukemia treated with anthracyclines. J Lab Clin Med. (2005) 145:212-20. doi: 10.1016/j.lab.2005.02.003

40. Kilickap S, Barista I, Akgul E, Aytemir K, Aksoyek S, Aksoy S, et al. cTnT can be a useful marker for early detection of anthracycline cardiotoxicity. Ann Oncol. (2005) 16:798-804. doi: 10.1093/annonc/mdi152

41. Lee HS, Son CB, Shin SH, Kim YS. Clinical correlation between brain natriutetic peptide and anthracyclin-induced cardiac toxicity. Cancer Res Treat. (2008) 40:121-6. doi: 10.4143/crt.2008.40.3.121

42. Schmidinger M, Zielinski CC, Vogl UM, Bojic A, Bojic M, Schukro $\mathrm{C}$, et al. Cardiac toxicity of sunitinib and sorafenib in patients with metastatic renal cell carcinoma. J Clin Oncol. (2008) 26:5204-12. doi: 10.1200/JCO.2007.15.6331

43. Cardinale D, Colombo A, Torrisi R, Sandri MT, Civelli M, Salvatici $\mathrm{M}$, et al. Trastuzumab-induced cardiotoxicity: clinical and prognostic implications of troponin I evaluation. J Clin Oncol. (2010) 28:3910-6. doi: 10.1200/JCO.2009.27.3615

44. Sawaya H, Sebag IA, Plana JC, Januzzi JL, Ky B, Cohen V, et al. Early detection and prediction of cardiotoxicity in chemotherapy-treated patients. Am J Cardiol. (2011) 107:1375-80. doi: 10.1016/j.amjcard.2011.01.006

45. Lipshultz SE, Scully RE, Lipsitz SR, Sallan SE, Silverman LB, Miller TL, et al. Assessment of dexrazoxane as a cardioprotectant in doxorubicin-treated children with high-risk acute lymphoblastic leukaemia: long-term followup of a prospective, randomised, multicentre trial. Lancet Oncol. (2010) 11:950-61. doi: 10.1016/S1470-2045(10)70204-7

46. Sawaya H, Sebag IA, Plana JC, Januzzi JL, Ky B, Tan TC, et al. Assessment of echocardiography and biomarkers for the extended prediction of cardiotoxicity in patients treated with anthracyclines, taxanes, and trastuzumab. Circ Cardiovasc Imaging. (2012) 5:596-603. doi: 10.1161/CIRCIMAGING.112.973321

47. Drafts BC, Twomley KM, D’Agostino R Jr, Lawrence J, Avis N, et al. Low to moderate dose anthracycline-based chemotherapy is associated with early noninvasive imaging evidence of subclinical cardiovascular disease. JACC Cardiovasc Imaging. (2013) 6:877-85. doi: 10.1016/j.jcmg.2012.11.017

48. Mornos C, Petrescu L. Early detection of anthracycline-mediated cardiotoxicity: the value of considering both global longitudinal left ventricular strain and twist. Can J Physiol Pharmacol. (2013) 91:601-7. doi: 10.1139/cjpp-2012-0398

49. Mavinkurve-Groothuis AM, Marcus KA, Pourier M, Loonen J, Feuth T, Hoogerbrugge PM, et al. Myocardial 2D strain echocardiography and cardiac biomarkers in children during and shortly after anthracycline therapy for acute lymphoblastic leukaemia (ALL): a prospective study. Eur Heart J Cardiovasc Imaging. (2013) 14:562-9. doi: 10.1093/ehjci/jes217

50. Ky B, Putt M, Sawaya H, French B, Januzzi JL Jr, Sebag IA, et al. Early increases in multiple biomarkers predict subsequent cardiotoxicity in patients with breast cancer treated with doxorubicin, taxanes, and trastuzumab. J Am Coll Cardiol. (2014) 63:809-16. doi: 10.1016/j.jacc.2013.10.061

51. Mornos C, Manolis AJ, Cozma D, Kouremenos N, Zacharopoulou I, Ionac A. The value of left ventricular global longitudinal strain assessed by threedimensional strain imaging in the early detection of anthracyclinemediated cardiotoxicity. Hellenic J Cardiol. (2014) 55:235-44.

52. Putt M, Hahn VS, Januzzi JL, Sawaya H, Sebag IA, Plana JC, et al. Longitudinal changes in multiple biomarkers are associated with cardiotoxicity in breast cancer patients treated with doxorubicin, taxanes, and trastuzumab. Clin Chem. (2015) 61:1164-72. doi: 10.1373/clinchem.2015.241232

53. Zardavas D, Suter TM, van Veldhuisen DJ, Steinseifer J, Noe J, Lauer S, et al. Role of troponins $\mathrm{I}$ and $\mathrm{T}$ and $\mathrm{N}$-terminal prohormone of brain natriuretic peptide in monitoring cardiac safety of patients with early-stage human epidermal growth factor receptor 2-positive breast cancer receiving trastuzumab: a herceptin adjuvant study cardiac marker substudy. J Clin Oncol. (2017) 35:878-84. doi: 10.1200/JCO.2015.65.7916

54. Olivieri J, Perna GP, Bocci C, Montevecchi C, Olivieri A, Leoni P, et al. Modern management of anthracycline-induced cardiotoxicity in lymphoma 
patients: low occurrence of cardiotoxicity with comprehensive assessment and tailored substitution by nonpegylated liposomal doxorubicin. Oncologist. (2017) 22:422-31. doi: 10.1634/theoncologist.2016-0289

55. Kitayama H, Kondo T, Sugiyama J, Kurimoto K, Nishino Y, Kawada M, et al. High-sensitive troponin T assay can predict anthracycline- and trastuzumabinduced cardiotoxicity in breast cancer patients. Breast Cancer. (2017) 24:774-82. doi: 10.1007/s12282-017-0778-8

56. Shafi A, Siddiqui N, Imtiaz S, Din Sajid MU. Left ventricular systolic dysfunction predicted by early troponin I release after anthracycline based chemotherapy in breast cancer patients. J Ayub Med Coll Abbottabad. (2017) 29:266-9.

57. Lenihan DJ, Stevens PL, Massey M, Plana JC, Araujo DM, Fanale MA, et al. The utility of point-of-care biomarkers to detect cardiotoxicity during anthracycline chemotherapy: a feasibility study. J Card Fail. (2016) 22:433-8. doi: 10.1016/j.cardfail.2016.04.003

58. Feola M, Garrone O, Occelli M, Francini A, Biggi A, Visconti G, et al. Cardiotoxicity after anthracycline chemotherapy in breast carcinoma: effects on left ventricular ejection fraction, troponin I and brain natriuretic peptide. Int J Cardiol. (2011) 148:194-8. doi: 10.1016/j.ijcard.2009.09.564

59. Sandri MT, Salvatici M, Cardinale D, Zorzino L, Passerini R, Lentati P, et al. $\mathrm{N}$-terminal pro-B-type natriuretic peptide after high-dose chemotherapy: a marker predictive of cardiac dysfunction? Clin Chem. (2005) 51:1405-10. doi: $10.1373 /$ clinchem. 2005.050153

60. Hoeger CW, Hayek SS. Role of cardiovascular biomarkers in the risk stratification, monitoring, and management of patients with cancer. Cardiol Clin. (2019) 37:505-23. doi: 10.1016/j.ccl.2019.07.015

61. Weir RA, Petrie CJ, Murphy CA, Clements S, Steedman T, Miller AM, et al. Galectin-3 and cardiac function in survivors of acute myocardial infarction. Circ Heart Fail. (2013) 6:492-8. doi: 10.1161/CIRCHEARTFAILURE. 112.000146

62. Freres P, Bouznad N, Servais L, Josse C, Wenric S, Poncin A, et al. Variations of circulating cardiac biomarkers during and after anthracyclinecontaining chemotherapy in breast cancer patients. BMC Cancer. (2018) 18:102. doi: 10.1186/s12885-018-4015-4

63. Oliveira-Carvalho V, Ferreira LR, Bocchi EA. Circulating mir-208a fails as a biomarker of doxorubicin-induced cardiotoxicity in breast cancer patients. $J$ Appl Toxicol. (2015) 35:1071-2. doi: 10.1002/jat.3185

64. Armenian SH, Gelehrter SK, Vase T, Venkatramani R, Landier W, Wilson KD, et al. Screening for cardiac dysfunction in anthracyclineexposed childhood cancer survivors. Clin Cancer Res. (2014) 20:6314-23. doi: 10.1158/1078-0432.CCR-13-3490

65. van Boxtel W, Bulten BF, Mavinkurve-Groothuis AM, Bellersen L, Mandigers CM, Joosten LA, et al.F. New biomarkers for early detection of cardiotoxicity after treatment with docetaxel, doxorubicin and cyclophosphamide. Biomarkers. (2015) 20:143-8. doi: 10.3109/1354750X.2015.1040839

66. Narayan HK, Finkelman B, French B, Plappert T, Hyman D, Smith AM, et al. Detailed echocardiographic phenotyping in breast cancer patients: associations with ejection fraction decline, recovery, and heart failure symptoms over 3 years of follow-up. Circulation. (2017) 135:1397-12. doi: 10.1161/CIRCULATIONAHA.116.023463

67. Thavendiranathan P, Poulin F, Lim KD, Plana JC, Woo A, Marwick TH. Use of myocardial strain imaging by echocardiography for the early detection of cardiotoxicity in patients during and after cancer chemotherapy: a systematic review. J Am Coll Cardiol. (2014) 63(25 Pt A):2751-68. doi: $10.1016 /$ j.jacc.2014.01.073

68. Brown J, Jenkins C, Marwick TH. Use of myocardial strain to assess global left ventricular function: a comparison with cardiac magnetic resonance and 3-dimensional echocardiography. Am Heart J. (2009) 157:102.e1-5. doi: 10.1016/j.ahj.2008.08.032

69. Liu J, Banchs J, Mousavi N, Plana JC, Scherrer-Crosbie M, Thavendiranathan $\mathrm{P}$, et al. Contemporary role of echocardiography for clinical decision making in patients during and after cancer therapy. JACC Cardiovasc Imaging. (2018) 11:1122-131. doi: 10.1016/j.jcmg.2018.03.025

70. Doherty JU, Kort S, Mehran R, Schoenhagen P, Soman P, Dehmer GJ, et al. ACC/AATS/AHA/ASE/ASNC/HRS/SCAI/SCCT/SCMR/STS 2019 Appropriate use criteria for multimodality imaging in the assessment of cardiac structure and function in nonvalvular heart disease: a report of the
American college of cardiology appropriate use criteria task force, American association for thoracic surgery, American heart association, American society of echocardiography, American society of nuclear cardiology, heart rhythm society, society for cardiovascular angiography and interventions, society of cardiovascular computed tomography, society for cardiovascular magnetic resonance, and the society of thoracic surgeons. J Am Coll Cardiol. (2019) 73:488-516. doi: 10.1016/j.jacc.2018.10.038.

71. Negishi T, Thavendiranathan P, Negishi K, Marwick TH, SUCCOUR Investigators. Rationale and design of the strain surveillance of chemotherapy for improving cardiovascular outcomes: the SUCCOUR trial. JACC Cardiovasc Imaging. (2018) 11:1098-105.

72. Smith LA, Cornelius VR, Plummer CJ, Levitt G, Verrill M, Canney P, et al. Cardiotoxicity of anthracycline agents for the treatment of cancer: systematic review and meta-analysis of randomised controlled trials. BMC Cancer. (2010) 10:337. doi: 10.1186/1471-2407-10-337

73. van Dalen EC, van der Pal HJ, Kremer LC. Different dosage schedules for reducing cardiotoxicity in people with cancer receiving anthracycline chemotherapy. Cochrane Database Syst Rev. (2016) 3:CD005008. doi: 10.1002/14651858.CD005008.pub4

74. Rafiyath SM, Rasul M, Lee B, Wei G, Lamba G, Liu D. Comparison of safety and toxicity of liposomal doxorubicin vs. conventional anthracyclines: a meta-analysis. Exp Hematol Oncol. (2012) 1:10. doi: 10.1186/2162-3619-1-10

75. Mehta LS, Watson KE, Barac A, Beckie TM, Bittner V, Cruz-Flores S, et al. American heart association cardiovascular disease in, C. Special populations committee of the council on clinical, C. council on, Stroke $\mathrm{N}$, C. council on quality of, and outcomes R. cardiovascular disease and breast cancer: where these entities intersect: a scientific statement from the American heart association. Circulation. (2018) 137:e30-e66. doi: 10.1161/CIR.0000000000000556

76. Brown S. Preventive cardio-oncology: the time has come. Front. Cardiovasc. Med. (2020). 6:187. doi: 10.3389/fcvm.2019.00187

77. Yin BA, Brewster AM, Barac A, Thoman W, Oeffinger KC, Gilchrist SC. Cardiovascular prevention strategies in breast cancer. J Am Coll Cardiol CardioOnc. (2019) 2:322-325. doi: 10.1016/j.jaccao.2019.09.001

78. Barish R, Lynce F, Unger K, Barac A. Management of cardiovascular disease in women with breast cancer. Circulation. (2019) 139:1110-20. doi: 10.1161/CIRCULATIONAHA.118.039371

79. Nitiss KC, Nitiss JL. Twisting and ironing: doxorubicin cardiotoxicity by mitochondrial DNA damage. Clin Cancer Res. (2014) 20:4737-9. doi: 10.1158/1078-0432.CCR-14-0821

80. EMA. European Medicines Agency. Assessment Report. DexrazoxaneContaining Medicinal Products. EMA (2011).

81. van Dalen EC, Caron HN, Dickinson HO, Kremer LC. Cardioprotective interventions for cancer patients receiving anthracyclines. Cochrane Database Syst Rev. (2011) CD003917. doi: 10.1002/14651858.CD003917.pub4

82. Reichardt P, Tabone MD, Mora J, Morland B, Jones RL. Risk-benefit of dexrazoxane for preventing anthracycline-related cardiotoxicity: reevaluating the European labeling. Future Oncol. (2018) 14:2663-676. doi: $10.2217 /$ fon-2018-0210

83. Asselin BL, Devidas M, Chen L, Franco VI, Pullen J, Borowitz MJ, et al. Cardioprotection and safety of dexrazoxane in patients treated for newly diagnosed T-cell acute lymphoblastic leukemia or advanced-stage lymphoblastic non-hodgkin lymphoma: a report of the children's oncology group randomized trial pediatric oncology group 9404. J Clin Oncol. (2016) 34:854-62. doi: 10.1200/JCO.2015.60.8851

84. EMA. European Medicines Agency. Questions and Answers on Cardioxane (Dexrazoxane: Powder for Solution for Injection: $500 \mathrm{mg}$ ). Outcome of a Procedure Under Article 13 of Regulation (EC) No 1234/2008. EMA (2017).

85. Macedo AVS, Lyon AR, Nascimento BR, Putzu A, Rossi L, Costa RB, et al. Efficacy of dexrazoxane in preventing anthracycline cardiotoxicity in breast cancer. J Am Coll Cardiol CardioOnc. (2019) 1:68-79. doi: 10.1016/j.jaccao.2019.08.003

86. Kalay N, Basar E, Ozdogru I, Er O, Cetinkaya Y, Dogan A, et al. Protective effects of carvedilol against anthracycline-induced cardiomyopathy. J Am Coll Cardiol. (2006) 48:2258-62. doi: 10.1016/j.jacc.2006.07.052

87. Kaya MG, Ozkan M, Gunebakmaz O, Akkaya H, Kaya EG, Akpek $M$, et al. Protective effects of nebivolol against anthracycline-induced 
cardiomyopathy: a randomized control study. Int J Cardiol. (2013) 167:230610. doi: $10.1016 /$ j.ijcard.2012.06.023

88. Seicean S, Seicean A, Alan N, Plana JC, Budd GT, Marwick TH. Cardioprotective effect of beta-adrenoceptor blockade in patients with breast cancer undergoing chemotherapy: follow-up study of heart failure. Circ Heart Fail. (2013) 6:420-6. doi: 10.1161/CIRCHEARTFAILURE.112.000055

89. Pituskin E, Mackey JR, Koshman S, Jassal D, Pitz M, Haykowsky MJ, et al. Multidisciplinary approach to novel therapies in cardio-oncology research (MANTICORE 101-Breast): a randomized trial for the prevention of trastuzumab-associated cardiotoxicity. J Clin Oncol. (2017) 35:870-77. doi: 10.1200/JCO.2016.68.7830

90. Cardinale D, Colombo A, Sandri MT, Lamantia G, Colombo N, Civelli $\mathrm{M}$, et al. Prevention of high-dose chemotherapy-induced cardiotoxicity in high-risk patients by angiotensin-converting enzyme inhibition. Circulation. (2006) 114:2474-81. doi: 10.1161/CIRCULATIONAHA.106.635144

91. Nakamae H, Tsumura K, Terada Y, Nakane T, Nakamae M, Ohta K, et al. Notable effects of angiotensin II receptor blocker, valsartan, on acute cardiotoxic changes after standard chemotherapy with cyclophosphamide, doxorubicin, vincristine, and prednisolone. Cancer. (2005) 104:2492-8. doi: $10.1002 / \mathrm{cncr} .21478$

92. Cadeddu C, Piras A, Mantovani G, Deidda M, Dessi M, Madeddu C, et al. Protective effects of the angiotensin II receptor blocker telmisartan on epirubicin-induced inflammation, oxidative stress, and early ventricular impairment. Am Heart J. (2010) 160:487 e1-7. doi: 10.1016/j.ahj.2010.05.037

93. Gulati G, Heck SL, Rosjo H, Ree AH, Hoffmann P, Hagve TA, et al. Neurohormonal blockade and circulating cardiovascular biomarkers during anthracycline therapy in breast cancer patients: results from the PRADA (prevention of cardiac dysfunction during adjuvant breast cancer therapy) study. J Am Heart Assoc. (2017) 6:006513. doi: 10.1161/jaha.117.006513

94. Akpek M, Ozdogru I, Sahin O, Inanc M, Dogan A, Yazici C, et al. Protective effects of spironolactone against anthracycline-induced cardiomyopathy. Eur J Heart Fail. (2015) 17:81-9. doi: 10.1002/ejhf.196

95. Bosch X, Rovira M, Sitges M, Domenech A, Ortiz-Perez JT, de Caralt TM, et al. Enalapril and carvedilol for preventing chemotherapy-induced left ventricular systolic dysfunction in patients with malignant hemopathies: the OVERCOME trial (prevention of left ventricular dysfunction with enalapril and carvedilol in patients submitted to intensive chemotherapy for the treatment of malignant hEmopathies). J Am Coll Cardiol. (2013) 61:2355-62. doi: 10.1016/j.jacc.2013.02.072

96. Acar Z, Kale A, Turgut M, Demircan S, Durna K, Demir S, et al. Efficiency of atorvastatin in the protection of anthracycline-induced cardiomyopathy. J Am Coll Cardiol. (2011) 58:988-9. doi: 10.1016/j.jacc.2011.05.025

97. Seicean S, Seicean A, Plana JC, Budd GT, Marwick TH. Effect of statin therapy on the risk for incident heart failure in patients with breast cancer receiving anthracycline chemotherapy: an observational clinical cohort study. J Am Coll Cardiol. (2012) 60:2384-90. doi: 10.1016/j.jacc.2012. 07.067

98. Chotenimitkhun R, D’Agostino R Jr, Lawrence JA, Hamilton CA, Jordan $\mathrm{JH}$, Vasu S, et al. Chronic statin administration may attenuate early anthracycline-associated declines in left ventricular ejection function. Can J Cardiol. (2015) 31:302-7. doi: 10.1016/j.cjca.2014.11.020
99. Vaduganathan M, Hirji SA, Qamar A, Bajaj N, Gupta A, Zaha V, et al. Efficacy of neurohormonal therapies in preventing cardiotoxicity in patients with cancer undergoing chemotherapy. J Am Coll Cardiol CardioOnc. (2019) 1:54-65. doi: 10.1016/j.jaccao.2019.08.006

100. Elitok A, Oz F, Cizgici AY, Kilic L, Ciftci R, Sen F, et al. Effect of carvedilol on silent anthracycline-induced cardiotoxicity assessed by strain imaging: a prospective randomized controlled study with six-month follow-up. Cardiol J. (2014) 21:509-15. doi: 10.5603/CJ.a2013.0150

101. Avila MS, Ayub-Ferreira SM, de Barros Wanderley MR Jr, das Dores Cruz F, Gonçalves Brandão SM, Rigaud VOC, et al. Carvedilol for prevention of chemotherapy-related cardiotoxicity: the CECCY trial. J Am Coll Cardiol. (2018) 71:2281-90. doi: 10.1016/j.jacc.2018.02.049

102. Oliveira PJ, Bjork JA, Santos MS, Leino RL, Froberg MK, Moreno AJ, et al. Carvedilol-mediated antioxidant protection against doxorubicin-induced cardiac mitochondrial toxicity. Toxicol Appl Pharmacol. (2004) 200:159-68. doi: 10.1016/j.taap.2004.04.005

103. Davis MK, Villa D, Tsang TSM, Starovoytov A, Gelmon K, Sean A, et al. Effect of eplerenone on diastolic function in women receiving anthracyclinebased chemotherapy for breast cancer. J Am Coll Cardiol CardioOnc. (2019) 2:295-8. doi: 10.1016/j.jaccao.2019.10.001

104. Gasser CA, Audebrand A, Daglayan A, Charavin M, B.Escoubet, Karpov $\mathrm{P}$, et al. Prokineticin receptor-1 signaling inhibits dose- and timedependent anthracycline-induced cardiovascular toxicity via myocardial and vascular protection. J Am Coll Cardiol CardioOnc. (2019) 1:84-102. doi: 10.1016/j.jaccao.2019.06.003

105. Audebrand A, Désaubry L, Nebigil CG. Targeting GPCRs against cardiotoxicity induced by anticancer treatments. Front. Cardiovasc. Med. 6:194. (2019). doi: 10.3389/fcvm.2019.00194

106. Cardinale D, Ciceri F, Latini R, Franzosi MG, Sandri MT, Civelli M, et al. Anthracycline-induced cardiotoxicity: a multicenter randomised trial comparing two strategies for guiding prevention with enalapril: the international cardiooncology society-one trial. Eur J Cancer. (2018) 94:12637. doi: 10.1016/j.ejca.2018.02.005

107. Cardinale D, Caruso V, Cipolla CM. The breast cancer patient in the cardioncology unit. J Thorac Dis. (2018) 10:S4306-22. doi: $10.21037 /$ jtd.2018.10.06

108. Ky B. JACC: CardioOncology: poised to serve a maturing, collaborative field. J Am Coll Cardiol CardioOnc. (2019) 1:131-132. doi: 10.1016/j.jaccao.2019.06.001

Conflict of Interest: The authors declare that the research was conducted in the absence of any commercial or financial relationships that could be construed as a potential conflict of interest.

Copyright $\odot 2020$ Cardinale, Iacopo and Cipolla. This is an open-access article distributed under the terms of the Creative Commons Attribution License (CC BY). The use, distribution or reproduction in other forums is permitted, provided the original author(s) and the copyright owner(s) are credited and that the original publication in this journal is cited, in accordance with accepted academic practice. No use, distribution or reproduction is permitted which does not comply with these terms. 